\title{
JOGAR VERSO, BORDAR MEMÓRIA, CANTAR POÉTICA: A PANDEMIA DE COVID-19 E AS MULHERES DO VALE DO JEQUITINHONHA
}

\author{
Débora Regina Bacega1
}

Resumo:

Este artigo apresenta as narrativas compreendidas nos jogos de versos das bordadeiras e tecelãs do Vale do Jequitinhonha durante a pandemia de Covid-19. O objeto teórico compreende as narrativas dessas mulheres. Por sua vez, o objeto empírico são os jogos de versos. Busca-se entender como essas narrativas corroboram com a memória oral e cultural dessa comunidade. Aciona-se as reflexões de lúri Lotman (1996), Jerusa Ferreira (1995), Paul Thompson (1998), Paul Ricoeur (2007), Herman Parret (1997), Jacques Rancière (2009), Ângela Marques e Marco Prado (2018). O corpus compreende os conteúdos publicados nos canais digitais versinhos.com.br e @rodadeversos. Esperase demonstrar como as práticas poéticas e estéticas desse grupo de mulheres acionam também a partilha da memória.

Palavras-chave: Comunicação e consumo; Partilha da memória; Covid-19. Mulheres; Vale do Jequitinhonha.

\begin{abstract}
:
This article presents the narratives that embroiderers and weavers have been playing with verses at Vale do Jequitinhonha during the Covid-19 pandemic. The theoretical object are these narratives. Playing with verses is the empirical object. The aim is to understand how these narratives can corroborate oral and cultural memory of this community. It presents reflections by lúri Lotman (1996), Jerusa Ferreira (1995), Paul Thompson (1998), Paul Ricoeur (2007), Herman Parret (1997), Jacques Rancière (2009) and Ângela Marques and Marco Prado (2018). The corpus comprehends content published in digital channels versinhos.com.br and @rodadeversos. The objective is to demonstrate how the poetic and aesthetic practices from this group of women also contribute to the memory sharing.
\end{abstract}

Keywords: Communication and consumption; Memory sharing; Covid-19; Women. Vale do Jequitinhonha.

\section{Considerações iniciais}

"Queimô o carvão / Quero ver carvão queimar / Eu danço com Marisa / Até poeira levantar (...)."2 Esse é o verso que Dona Nilza joga para Marisa. Jogar verso ${ }^{3}$, como se diz na região do Vale do Jequitinhonha, é uma tradição comum aos rituais das festas,

\footnotetext{
${ }^{1}$ Doutoranda e mestre em Comunicação e Práticas de Consumo pelo PPGCOM ESPM/SP. Bolsista CAPES-PROSUP. Integrante do MNEMON, Grupo de Pesquisa em Memória, Comunicação e Consumo, certificado pelo CNPq/ESPM. Possui MBA Executivo em Marketing de Serviços pela ESPM, com especialização complementar em Gestão Internacional de Negócios pela Universidad Nebrija (Espanha). Bacharel em Jornalismo pela Faculdade Cásper Líbero. Graduada em Publicidade e Propaganda pela ESPM. Vivência profissional em comunicação e marketing. E-mail: deborabacega@gmail.com

2 Roda de versos [Post do Instagram]. Disponível em: <https://www.instagram.com/p/CBi-t3qAgf-/> Acesso em: 17 jun. 2020.

${ }^{3}$ Versinhos de Bem-Querer. [Site Institucional]. Disponível em <versinhos.com.br.> Acesso em: 13 jun. 2020.
} 
celebrações ou encontros das comunidades ${ }^{4}$. Celebra-se o nascimento de filhos, por exemplo, jogando versos. A prática consiste em reunir as pessoas da comunidade e jogar versos, ou seja, uma pessoa canta um refrão, entremeado de versos, ora de improviso, ora do repertório do grupo, podendo desafiar outro integrante a dar continuidade à roda de versos que vai se compondo. Dona Mila, Nêga, Marli, Karen, Luciana, Dona Niva, Nalva, Jac, Leila e Elaine fazem parte do grupo de mulheres que são bordadeiras, tecelãs, batuqueiras e jogadoras de versos. Elas cantam e jogam verso enquanto colhem, batem, fiam e tingem o fio de algodão, utilizando, por exemplo, cascas e raízes de plantas 5 .

Essas mulheres são atravessadas pela pandemia de Covid-19, que atingiu as rotas, os bordados, os sorrisos e as cantigas de sete comunidades rurais, em três municípios distintos: Tocoiós e São João de Baixo, no município de Francisco Badaró, Curtume e Ribeirão de Areia, no município de Jenipapo de Minas, Poções, Alves e São João dos Marques, no município de Chapada do Norte ${ }^{6}$. Os encontros e as festas da comunidade, assim como, as feiras foram suspensas em função do isolamento social prescrito durante o primeiro semestre de 2020. Além de afastadas, essas comunidades rurais têm difícil acesso aos centros de atendimento médico. Tudo deu lugar à preocupação, à proteção e, não menos, à miséria. De acordo com o Programa Polo de Integração da UFMG no Vale do Jequitinhonha $^{7}$, a região apresenta um dos menores índices de desenvolvimento socioeconômico do Estado de Minas Gerais, além de sofrer os constantes impactos ambientais das atividades de mineradoras e carvoarias. Por esses motivos, também é conhecida como Vale da pobreza.

Em busca da sustentabilidade financeira e da visibilidade dessas comunidades, o site Versinhos de Bem-Querer ${ }^{8}$ e a @rodadeversos, página do grupo na rede social Instagram ${ }^{9}$, foram criados com o apoio da ONG AJENAI (Associação Jenipapense de Assistência à Infância) ${ }^{10}$. Nesses canais, são divulgados vídeos nos quais as jogadoras de verso, em sua maioria, bordadeiras do Curtume e tecelãs de Tocoiós, aparecem cantando poesia. No site, há uma loja virtual na qual é possível encomendar um versinho de bem-

\footnotetext{
${ }^{4}$ Idem

${ }^{5}$ Casa Vogue Online. Bordadeiras do Vale do Jequitinhonha apresentam coleção de estandartes. Publicado em 6 dez 2018. Disponível em: <https://casavogue.globo.com/Design/Objetos/noticia/2018/12/bordadeiras-dovale-do-jequitinhonha-apresentam-colecao-de-estandartes.html> Acesso em: 16 jun. 2020.

${ }^{6}$ Versinhos de Bem-Querer. [Site Institucional]. Disponível em <versinhos.com.br.> Acesso em: 13 jun. 2020

7 Polo Jequitinhonha UFMG [Site Institucional]. Disponível em <https://www.ufmg.br/polojequitinhonha/ovale/sobre-o-vale-do-jequitinhonha/.> Acesso em: 17 jun. 2020.

${ }^{8}$ De acordo com o site Versinhos de Bem-Querer, o projeto tem a idealização e o apoio da ONG AJENAI, situada em Jenipapo de Minas, no Vale do Jequitinhonha.

${ }^{9}$ Ibidem

10 Mais informações no site <https://www.ajenai.org.br/.>
} 
querer pelo valor de vinte e seis reais. Já a gravação do áudio dos versos é enviada pelo WhatsApp no prazo de dez dias após a realização do pagamento on-line.

Por outro lado, percebemos o uso das linguagens oral, imagética, escrita, corpórea nas narrativas das rodas de versos. Nesse sentido, o objetivo deste artigo é apresentar e analisar as narrativas compreendidas nos jogos de versos das bordadeiras e tecelãs do Vale do Jequitinhonha durante a pandemia de Covid-19. O objeto teórico compreende as narrativas dessas mulheres. Escolhemos os jogos de versos como objeto empírico. Buscamos problematizar como essas narrativas corroboram com a memória oral e da cultura dessa comunidade. O corpus compreende os conteúdos publicados nos canais digitais versinhos.com.br e na página @rodadeversos. Para sustentar nossa análise, acionamos as contribuições de lúri Lotman (1996), Jerusa Ferreira (1995; 1996), Paul Thompson (1998; 2006), Paul Ricoeur (2007). Também recorremos às reflexões de Edgar Morin (1973), Herman Parret (1997), Jacques Rancière (2009), Ângela Marques e Marcos Prado (2018) e José Eugenio de Menezes (2004).

\title{
Jogar versos: vozes e saberes
}

No Vale do Jequitinhonha, pode-se jogar versos sozinha, na maioria das vezes, para outra pessoa presente na roda. No entanto, por conta da pandemia de Covid-19, as jogadoras não estão se reunindo fisicamente. Assim, cada jogadora convida outra participante para entrar na roda virtual. Já os versos podem ser criados de improviso ou extraídos do repertório tradicional da região.

Por outro lado, identificamos que esses versos são cantados em quadradinhas ${ }^{11}$. Neste formato de texto poético, cada estrofe tem quatro versos (linhas) com sete sílabas cada um, sendo que a rima acontece entre as sílabas tônicas das últimas palavras das linhas dois e quatro. Para ilustrarmos essa dinâmica, apresentamos a transcrição dos versos da jogadora Marli:

\author{
Queimô carvão \\ Quero ver carvão queimar \\ Eu canto para Nêga \\ Até o dia clarear
}

\footnotetext{
${ }^{11}$ Roda de versos [Post do Instagram]. Disponível em: <https://www.instagram.com/p/CBk86KQHYOh/.> Acesso em:16 jun. 2020.
} 
Nêga é bonita,

Bonitinha Nêga é

Parece um cravo branco

Nos pezin de São José

Ah quem me dera

Uma chuva bem fininha

Pra molhar a sua cama

A Nêga vim dormir na minha ${ }^{12}$

Como podemos notar, Marli mantém a quadradinha, rimando as sílabas tônicas das últimas palavras das linhas dois e quatro. Percebemos que essas rimas são criadas tanto a partir do repertório da região, como os versos que se referem ao carvão (e, talvez, às carvoarias) quanto do improviso, como "Nêga é / São José e bem fininha / na minha". Assim, por meio de seus versos, a bordadeira Marli chama a jogadora Nêga para a roda.

Figura 1. Tela capturada da publicação do vídeo da jogadora de versos Marli

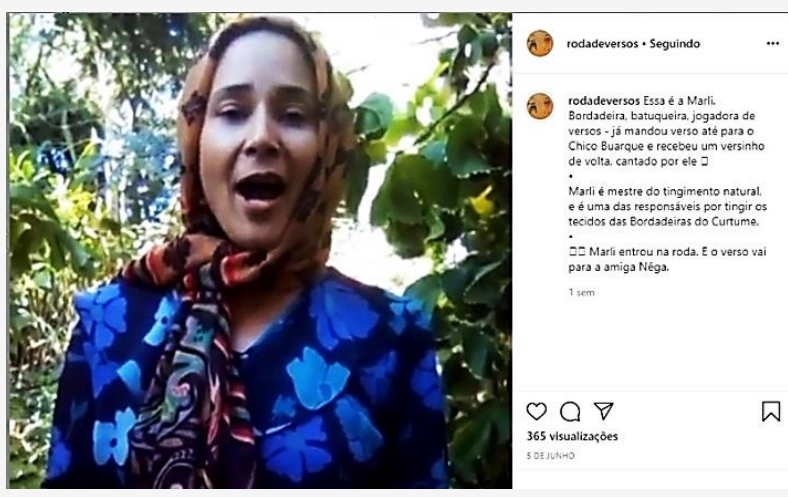

Fonte: Instagram @rodadeversos ${ }^{13}$.

Destacamos também as marcas da oralidade no ato de jogar versos: "queimô, pezin, pra, vim" passam a ser registradas e fixadas por meio da gravação e publicação de um vídeo nos canais digitais (vide figura 1). Conforme reportagem veiculada no jornal Folha de S. Paulo ${ }^{14}$, Marli jogou versos também para o compositor e cantor Chico Buarque a pedido de sua filha Helena Buarque. Por sua vez, Chico jogou versos para Marli: "Durante a noite inteira / Escuto como quem sonha / A Marli bordadeira / Lá de Jequitinhonha"15. A

\footnotetext{
12 Roda de versos [Post do Instagram]. Disponível em: <https://www.instagram.com/p/CBDXMFrAmCz/>Acesso em: 11 jun. 2020. 13 Idem

14 Folha de S. Paulo. Publicado em 9 jun. 2020. Disponível em: <https://www1.folha.uol.com.br/empreendedorsocial/2020/06/bordadeiras-de-minas-espalham-bem-quererem-versos-durante-isolamento.shtml.> Acesso em: 12 jun. 2020.

15 Idem
} 
bordadeira, que aprendeu a jogar verso com seus pais na infância, revela como cria seus versos: “Aqui é assim, você olha para uma pessoa e já pensa como ela é, e aí versa [de improviso]" 16 .

No que diz respeito à partilha de saberes (jogar verso) e ofícios (bordar, fiar e tecer), Jerusa Ferreira (1996), explica que as narrativas orais, fundamentadas a partir de um repertório inicial, sustentam a memória e transmissão de ofícios e saberes. A pesquisadora afirma que essas narrativas são os fios conectores entre a transmissão de saberes hierárquicos e organizados e os grupos sociais aos quais pertencem, sendo considerados vetores da comunicação: “as coisas e sua nomeação, a natureza e seus domínios, os mistérios do conhecimento" (FERREIRA, 1996, p. 103). Sob essa ótica, a autora revela que é da memória do mestre de um ofício que se inaugura e se projeta a construção de saberes, mantendo a futura coesão ao grupo (FERREIRA, 1996).

Já o sociólogo Paul Thompson (1998, 2006), em seus estudos sobre a história oral, destaca a relevância da oralidade na composição de narrativas. 0 autor define a voz como simples, epigramática e representativa. Por meio dela, é possível "trazer o passado até o presente", alterando a textura e o conteúdo da história (THOMPSON, 1998, p. 334). A coletânea de narrativas surge no processo de escuta e de registro das histórias de vida dos indivíduos, o que torna possível, na visão do sociólogo, a "construção de uma interpretação histórica mais ampla" e representativa (THOMPSON, 1998, p. 303).

$\mathrm{Na}$ condição de defensor do caráter multidisciplinar da história oral, Thompson (2006) afirma que muitos papéis sociais ainda são exercidos essencialmente pela oralidade como as cerimônias matrimoniais, os ritos religiosos, além das áreas de conhecimento pautadas pelas histórias familiares e pela transmissão de saberes e ofícios profissionais. Nesse sentido, para o sociólogo, o relato memorialístico é essencialmente oral, ainda que tenha o apoio de suportes escritos. Na visão do autor, a história oral faz parte do patrimônio cultural de comunidades ou grupos sociais (THOMPSON, 2006).

O historiador e filósofo Paul Ricoeur (2007, p.138), explica que, em sua fase declarativa, a memória entra na região da linguagem: "a lembrança dita, pronunciada, já é uma espécie de discurso que o sujeito trava consigo mesmo". Nesse sentido, Ricoeur aponta que esse discurso é pronunciado na língua comum, materna, e, consequentemente, dos outros. Assim, uma vez colocada na via da oralidade, a rememoração também se faz pela narrativa. Sob essa perspectiva, os estudos sobre a fenomenologia da memória do

16 Ibidem

// REVISTA DISPOSITIVA, v. 9, n. 16, p. 107-123 - ago/dez (2020) 
filósofo esboçam a passagem do olhar interior ao olhar exterior, da memória individual à coletiva. Desse modo, Ricoeur (2007) propõe que a memória seja resultado da relação tríplice de atribuição da lembrança: o eu, os coletivos e os próximos. Nesse sentido, a memória como narrativa também se configura como uma reconstrução ficcional.

Para o historiador, não existe uma memória por si mesma, mas sim a vontade de memória como condição para evitar o esquecimento. Por depender desse esforço laborioso, a própria memória se torna objeto de disputas, usos e abusos na proposição do que deve ser lembrado e do que deve ser esquecido. Sob essa ótica, o historiador ressalta a importância dos rastros mnésicos como a memória do corpo e a dos lugares na condição de "guardiões da memória pessoal e coletiva" (RICOEUR, 2007, p. 60).

A partir das contribuições de Ferreira (1996), Thompson (1998; 2006) e Ricoeur (2007), percebemos a transmissão e a rememoração de saberes e ofícios por meio da narrativa que se estabelece na oralidade do jogo de verso. A composição da quadradinha se dá pela combinação da narrativa memorialística de cada jogadora, do repertório musical tradicional e das atividades cotidianas como, por exemplo, bordar e tecer. Retomando à publicação de Marli, podemos inferir que as narrativas orais, os rastros mnésicos (corporais e locais), a memória de saberes dessa comunidade se tornam relevantes nas disputas de quem pode lembrar (atribuição de lembrança) e na luta contra o esquecimento dessas comunidades enquanto grupos sociais e culturais.

\section{Bordar memória: fronteiras semióticas e trocas culturais}

lúri Lotman (1996) propõe que cultura e memória são sinônimas quando há o entrelaçamento de dois ou mais textos culturais na geração de novos textos ressignificados. Por sua vez, ocorre a semiose entre todos dos signos e todos os códigos nas semiosferas de acordo com os estudos do semioticista, que é também um dos fundadores da Escola de Tártu-Moscou.

Lotman entende o sistema semiótico como o espaço da relação entre todos os signos e não apenas da ação de um único signo isolado. Para o semioticista, assim como nenhum organismo pode sobreviver isolado num ambiente da crosta terrestre, mas somente em inter-relação com outros organismos e em equilíbrio com este ambiente, o homem não pode viver apartado do mundo das línguas, signos, símbolos, mas somente num 
continuum semiótico. Lotman dá o nome de semiosfera a esse continuum semiótico, por analogia ao conceito de biosfera introduzido por V. I. Vernadski (LOTMAN, 1996).

Um dos conceitos fundamentais do caráter semiótico delimitado é o da fronteira que, em suas palavras, se define pelo "mecanismo bilíngue que traduz mensagens externas para o ambiente interno da semiosfera e vice-versa" (LOTMAN, 1996, p. 14). Dessa forma, somente por meio da fronteira é que a semiosfera pode ter contato com os espaços nãosemióticos e alosemóticos, além da realidade extra semiótica. Em outras palavras, como uma membrana celular, a semiosfera tem fronteiras que filtram o que está no seu exterior. Quando um determinado texto passa pela fronteira de uma semiosfera a outra, uma nova intersecção ocorre entre dois espaços semióticos.

Há nesse processo a transformação da não-cultura em cultura a partir do caráter informacional dos textos culturais por meio do mecanismo da fronteira entre duas ou mais semiosferas. De acordo com Lotman (1996), o bilinguismo cultural permitiu os contatos semióticos entre povos ou culturas distintas. Analogamente, essa se torna a função da fronteira da semiosfera em relação às "misturas [ou trocas] culturais" (LOTMAN, 1996, p. 14).

Dessa forma, para Lotman, a memória da cultura não é apenas uma, mas se torna internamente bastante variada, quando sua unidade existe somente em certo nível correspondente à organização interna das coletividades, constituindo o mundo de uma determinada cultura, como podemos observar nas palavras do semioticista:

\begin{abstract}
o espaço da cultura pode ser definido como um espaço de memória comum, isto é, um espaço em que alguns textos comuns podem ser preservados e atualizados. A atualização desses textos se realiza dentro dos limites de algumas variantes de sentido que permite dizer que no contexto de uma nova época o texto conserva, com toda a variância de interpretações, a qualidade de ser idêntico a si mesmo. Assim a memória comum de uma determinada cultura está assegurada, em primeiro lugar, pela presença constante de alguns textos e, em segundo lugar, pela unidade dos códigos, por sua invariância, ou pelo caráter ininterrupto e regular de sua transformação (LOTMAN, 1996, p. 109).
\end{abstract}

Em diálogo com os estudos de Lotman até aqui apresentados, reconhecemos que o mecanismo operador da tradução de textos em memória é a cultura. Ainda citando Ferreira (1995, p.117), o texto cultural não é a realidade propriamente dita, mas "somente aquilo que foi traduzido como patrimônio da memória”. Nesse sentido, podemos afirmar que os jogos de versos são textos da cultura que permanecem atualizados quando as 
fronteiras semióticas das semiosferas dos saberes e ofícios das bordadeiras e tecelãs, das quadradinhas e danças locais sofrem intersecções. Nesse movimento, alguns textos passam a fronteira, outros não. Para embasar nossa análise, apresentamos a transcrição do jogo de verso da Dona Ana:

\author{
O fogo quando apaga na senzala \\ Fica o calor \\ Do amor que se despreza \\ No coração fica a dor \\ Queimô carvão \\ Quero ver carvão queimar \\ Canto pra madinha Sena \\ Até poeira levantar \\ Cadê madinha Sena \\ Pra me ajudar a cantar \\ Quando nois cantava junto \\ Fazia até nois chorar ${ }^{17}$
}

Figura 2. Telas capturadas do vídeo da jogadora de versos Dona Ana

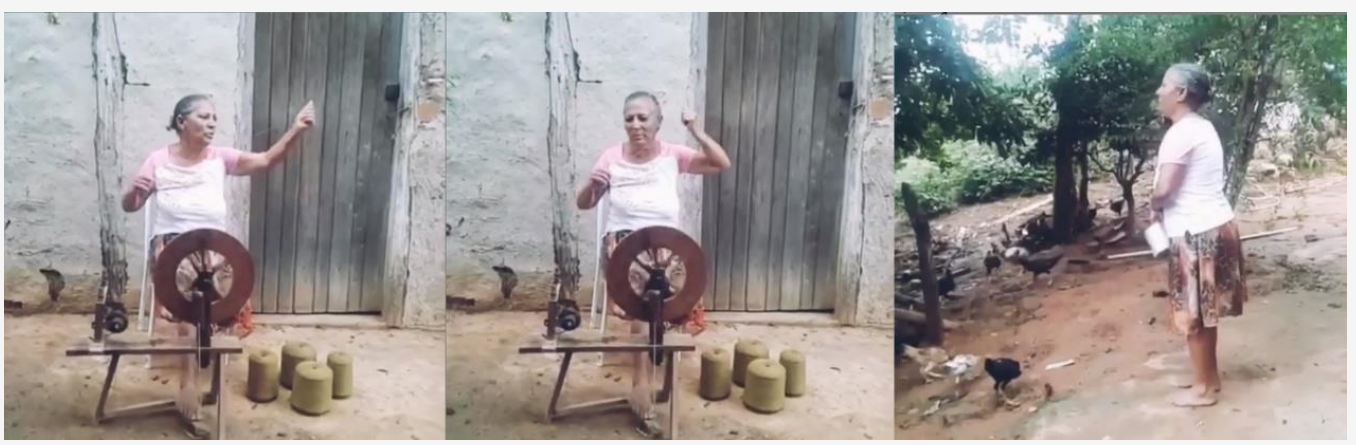

Fonte: Instagram @rodadeversos ${ }^{18}$.

Ao cantar seus versos, Dona Ana compõe uma narrativa que aborda o fogo, a senzala, amor, dor, carvão, além de procurar por “madinha Sena”, outra jogadora de versos, por quem sente, talvez, saudades como podemos notar na última estrofe: "Cadê madinha Sena/ Pra me ajudar a cantar / Quando nois cantava junto / Fazia até nois chorar". Podemos inferir que, graças à intersecção das fronteiras semióticas, um novo texto da cultura se cristaliza na quadradinha uma vez que senzala, fogo, carvão são textos

\footnotetext{
${ }_{17}$ Roda de versos [Post do Instagram]. Disponível em: <https://www.instagram.com/p/CBVodFxg3zC/> Acesso em: 12 jun. 2020.

18 Idem
} 
culturais geradores de novos textos nos textos, o que evidencia as trocas culturais entre os espaços semióticos como se refere Lotman (1996).

Destacamos, em nossa análise, as cenas (vide figura 2) de Dona Ana jogando versos enquanto fia o algodão ou dá comida aos patos convertidas em vídeo publicado na rede social. Trata-se de um texto da cultura, neste caso, gerado pela intersecção das fronteiras semióticas das semiosferas midiática, comunicacional e do consumo. Explicamos: o vídeo foi divulgado na internet acompanhado do seguinte conteúdo: “Dona Ana é uma mulher forte. Ela é também uma artista que fia, bate o algodão e tece lindamente. Ela gosta de cantar. E também [sic] de rezar. E a avó do Diogo, autor das ilustrações dos bordados do Curtume." ${ }^{19}$. Consideramos essa publicação na rede social uma peça publicitária, que também é um texto da cultura, quando qualifica a jogadora e os tipos de versos sob encomenda que podem ser adquiridos pela loja virtual, como mencionamos na introdução deste artigo.

Até aqui, refletimos com Ferreira, Thompson, Ricoeur e Lotman sobre vozes, saberes e memórias das mulheres do Vale do Jequitinhonha. A seguir, nossa discussão se amplia para poética, estética e corpo-mídia.

\section{Cantar poética: sensibilidades estéticas e corpos-mídia}

Edgar Morin (1973, p. 99) afirma que, diante da consciência de sua finitude por meio da morte, o homem passa a buscar "em seu duplo a sua existência mental", dando sentido a rituais, magias, estéticas. 0 pensador francês explica que a presença do duplo se revela pela imagem a exemplo de nosso reflexo desdobrado na água. Consequentemente, todo objeto tem uma dupla existência, como explica Morin (1973, p. 99): “pela palavra, pelo sinal, pelo grafito, pelo desenho, o objeto adquire uma existência mental mesmo fora de sua presença". Nesse sentido, a linguagem passa a designar a presença do duplo, o que interliga o homem imaginário ao homem imaginante. Por meio da arte, este homem imaginante não só vai reproduzir formas, mas inventá-las de forma a satisfazer "um prazer, uma emoção, propriamente estéticas” (MORIN, 1973, p. 102). Em decorrência desse processo, há a expansão e o enriquecimento da afectividade que se traduz em sensibilidade estética, ou seja, a relação entre o ser humano e a combinação de formas visuais, sonoras (ritmos, música, canto), corporais (dança) e sensoriais (odores e

19 Ibidem 
perfumes), como aponta o filósofo: “a sensibilidade estética é bem uma aptidão para entrar em ressonância, em harmonia, em sincronismo, com sons, odores, formas, imagens, cores, que são profundamente produzidos não só pelo universo, mas também (...) pelo Homo sapiens" (MORIN, 1973, p. 103).

Herman Parret (1997) define estética como fundamento comunicacional do ser-emcomunidade que se integra ao estar-em-comunidade graças ao sensus communis, uma vez que a temporalidade dá significação aos discursos e às produções humanas. Em outras palavras, o ser-em-comunidade desperta para as potencialidades do afeto do sensus communis (sensibilidade comum a todos), conectando-se a uma comunidade afetiva, e não argumentativa ou consensual. O sensus communis, por sua vez, se caracteriza pela tensão entre socializar o sensível e sensibilizar o social. A solução dessa tensão leva à concepção da comunidade afetiva por meio de uma experiência fusional sinestésica (socialização do sensível) e intercorpórea (sensibilização do social), como o autor explica neste trecho:

Podemos dizer que, de um lado, o sensus communis é uma sinestesia (é o movimento de socializar o sensível) e, de outro, é intercorporeidade (o movimento de sensibilização do social). É somente nesse duplo movimento e por meio dele que conseguimos resolver a tensão entre o social e o sensível e pensar a fusão, modo pelo qual a comunidade afetiva se realiza. A eufonia de vozes e de sentimentos depende de sua fusão. Essa fusão é melódica, já que ela é essencialmente temporalizada (PARRET, 1997, p. 198).

Dessa forma, para o autor, a estética do sensus communis legitima toda prática intersubjetiva da vida cotidiana por conta do movimento fusional nessa comunidade afetiva. Nesse sentido, a dimensão política da comunicação estética se encontra na intersecção entre o social e o sensível que valoriza a solidariedade no afeto (PARRET, 1997).

Jacques Rancière (2009) entende estética como a partilha do sensível que dá forma à comunidade, uma vez que essa partilha acaba por fixar, ao mesmo tempo, "um comum partilhado e partes exclusivas" (RANCIĖRE, 2009, p. 15). A repartição de partes exclusivas se refere à partilha de espaços, tempos e atividades que determina como esse comum se apresenta e como os outros indivíduos participam desta partilha. O filósofo argumenta ainda que a política é estética na medida em que é um modo de determinação do sensível, que se ocupa dos espaços reais e simbólicos, dos tempos, da visibilidade do que é próprio e do que é comum (RANCIÈRE, 2009). 
Em sua obra $A$ noite dos proletários (1988), após analisar cartas e documentos de operários no século XIX, o pensador francês descreve o conteúdo desse material como narrativas, textos literários e filosóficos. A partir dessa experiência, Rancière delineia seu método de igualdade, tendo como princípio a poética do conhecimento que consiste na literaridade, ou seja, a habilidade do indivíduo ou do coletivo de expressar suas narrativas (fabulações literárias ou criações ficcionais) por meio da linguagem. Uma vez que essas narrativas entram em circulação, temos a ruptura dos sistemas de classificações hierarquizantes de saberes e enunciados e, consequentemente, a operação dissensual e política da partilha do sensível de acordo com as reflexões de Rancière (MARQUES; PRADO, 2018).

Retornamos às nossas análises, destacando o jogo de verso da Dona Oraci. Nele, ela faz menção à pandemia de Covid-19 e ao uso de máscara como transcrevemos a seguir:

\author{
Carvão queimô \\ Quero ver carvão queimar \\ Eu canto mais a Niva \\ Até o dia clarear \\ Vou dá minha despedida \\ $\mathrm{Na}$ fornalha sem suspirus \\ Tô fazendo essas máscaras \\ Pra proteger do coronavírus ${ }^{20}$
}

Já as cenas se iniciam com a jogadora recitando a quadradinha acima enquanto olha para câmera e borda as máscaras. Ao dizer "Tô fazendo essas máscaras/ pra proteger do coronavírus", Dona Oraci adiciona a proteção ao rosto, como ilustra a figura 3.

Figura 3. Telas capturadas do vídeo da jogadora de versos Dona Oraci

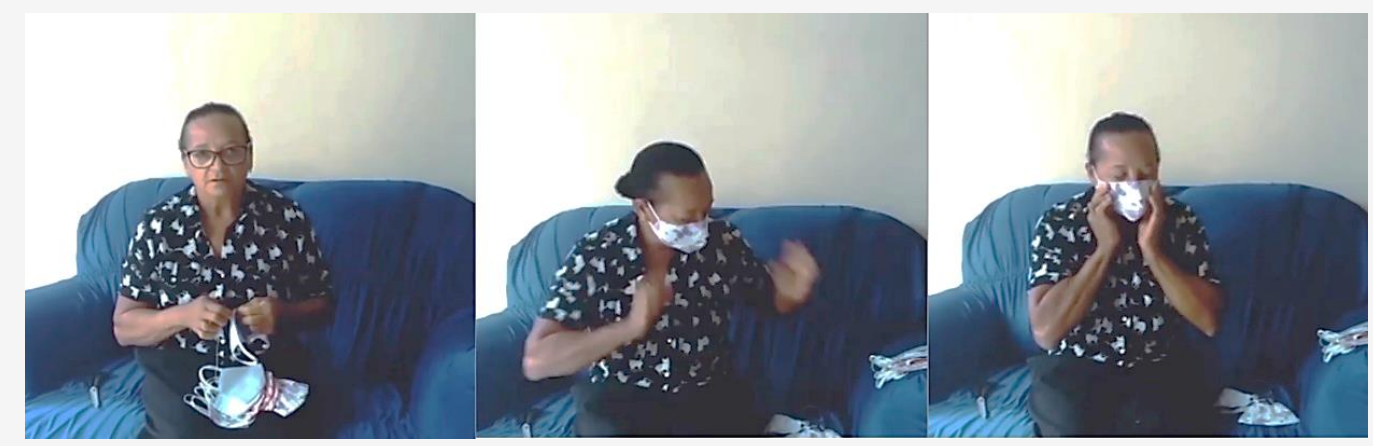

Fonte: Instagram @rodadeversos ${ }^{21}$.

${ }^{20}$ Roda de versos [Post do Instagram]. Disponível em: <https://www.instagram.com/p/CBdxTalFKA4/> Acesso em: 15 jun. 2020 
Os versos e as cenas do vídeo de Dona Oraci abordam explicitamente a proteção em relação à Covid-19, o que nos permite inferir a presença da comunidade afetiva a que se refere Parret (1997). As vozes das bordadeiras e tecelãs sensibilizadas e entrelaçadas no social são fusionadas na solidariedade do afeto em relação ao momento pandêmico. Por outro lado, também podemos visualizar a formação de uma segunda comunidade afetiva que se sensibiliza e se funde com as narrativas dessas mulheres por meio do consumo dos jogos de versos. Entendemos que consumir bens físicos ou simbólicos pressupõe compartilhar seus respectivos significados culturais. Nesse processo, as práticas de consumo se estruturam como sistema de linguagem (DOUGLAS; ISHERWOOD, 2006). Assim, compreendemos que os consumidores dos Versinhos de Bem-Querer formam uma comunidade afetiva ao promoverem o consumo físico, simbólico e midiático dos jogos de versos tanto na loja virtual quanto nas redes sociais.

Ainda em relação à estética, em diálogo com as reflexões de Rancière, podemos inferir que o ato de Dona Oraci de vestir a máscara ao mesmo tempo que canta os versos também revela a partilha política do sensível: sua narrativa e os movimentos de seu corpo comunicam o apoio ao uso de proteção em oposição, talvez, ao comportamento daqueles que ainda desconsideram as recomendações médicas e sanitárias. Assim como a comunidade, os jogos de versos são atravessados pela urgência dessa temática quando pensamos com Morin a combinação de formas visuais, sonoras, gestuais que exteriorizam a sensibilidade estética dessas mulheres diante dos efeitos da pandemia, refletindo a nossa impermanência e finitude. Por outro lado, quando as palavras coronavírus e máscara passam a fazer parte dos jogos de versos do Vale do Jequitinhonha, percebemos também a atualização destes textos culturais em referência às contribuições de Lotman (1996) já apresentadas.

Baitello (2010, p. 62), em diálogo com os estudos sobre Teorias de Mídias de Harry Pross, explica que "sempre há um corpo no início e no final de todo processo de comunicação", independente do grau de complexidade da mediação primária, secundária e terciária. Desse modo, o autor afirma que Pross ampliou o conceito de mídia, ressaltando que um gesto do corpo também comunica (BAITELLO, 2010). Já o pesquisador José Eugenio de Menezes (2004), também em consonância com as contribuições de Pross, elucida que: na mídia primária, este corpo se comunica presencialmente pelos sons, gestos ou odores;

21 Idem 
na mídia secundária, o mesmo corpo se expande por meio de artefatos (máscaras, pinturas, adereços) ou equipamentos adicionados; na terciária: todos os corpos envolvidos usam ferramentas como telas, TV, rádio, internet durante a comunicação. No entanto, Menezes reitera que existe interação e complementariedade entre as três categorias, ressaltando a importância dos vínculos entre os corpos e as mídias primária, secundária e terciária. Uma vez estabelecida nos processos comunicativos, essa teia de corpos vinculados pode tanto atar (nós) quanto desatar (os outros) indivíduos, dimensionando as relações entre comunicação e cultura (MENEZES, 2004).

Pensando com Baitello (2010) e Menezes (2004), podemos afirmar que o corpo da jogadora de versos Dona Oraci é mídia secundária quando ela põe a máscara em seu rosto, porém, este corpo é mídia terciária em sua imagem transmitida na página @rodadeversos: há uma tela entre nós e ela, porém, como nos lembra Menezes, os corpos estão vinculados ainda que fisicamente separados. Assim, podemos afirmar que os corpos das jogadoras da roda de versos são mídias terciárias.

Exemplo de corpo como mídia terciária, apresentamos também a jogadora Marisa, cujos versos transcrevemos:

\author{
Queimô carvão \\ Quero ver carvão queimar \\ Eu danço com Mariinha \\ Até poeira levantar \\ O batuque é uma dança \\ De cultura popular \\ Eu convido a Mariinha \\ Pra nois batuca ${ }^{22}$
}

Figura 4. Telas capturadas do vídeo da jogadora de verso Marisa

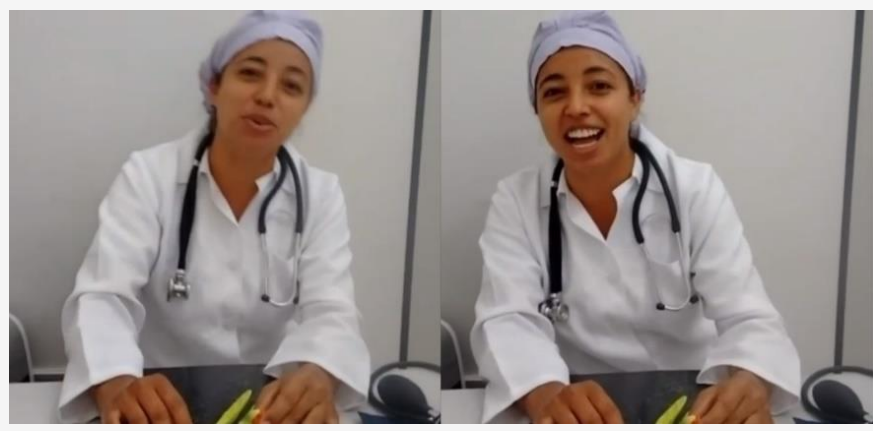

Fonte: Instagram @rodadeversos ${ }^{23}$.

${ }^{22}$ Roda de versos [Post do Instagram]. Disponível em: <https://www.instagram.com/p/CBnlaM3nwun/.> Acesso em: 18 jun. 2020. 
Conforme texto publicado no Instagram, Marisa também pertence à comunidade do Curtume. Filha e irmã de bordadeiras e jogadoras de verso, formou-se como técnica de enfermagem e trabalha em Araçuaí, cidade do Médio Jequitinhonha. Também é mãe e fica fisicamente longe do Curtume, mas "não podia ficar fora dessa roda"24. Em outra publicação na mesma rede social, lemos a explicação sobre o batuque como: “manifestação musical presente no Vale do Jequitinhonha, herança da matriz africana à cultura da região. Um grupo de tocadores de caixas, pandeiros, sanfona ou violão (às vezes viola ou cavaquinho) puxa o batuque, que vem acompanhado de refrões intercalados por versos $^{25}$.

A ideia de que Marisa, ainda que distante, não possa ficar fora da roda de versos nos faz retomar as reflexões de Morin, Parret e Rancière. Em relação a Morin, destacamos o batuque como sensibilidade estética. Sentada, Marisa canta e movimenta seu corpo para direita e para esquerda (vide figura 4) como se estivesse dançando na roda. Já com Parret, percebemos o ser-em-comunidade que se sensibiliza e se entrelaça no social quando a enfermeira e jogadora de versos fala sobre uma dança que as une na solidariedade do afeto pela cultura da região. Apesar de não morar no Curtume como as demais jogadoras, a permanência de Marisa na roda se dá por um movimento fusional que nos permite pensar a própria roda virtual de versos como sinônimo de comunidade afetiva.

Nesse sentido, é também na roda de versos que ocorre a partilha política do sensível a que se refere Rancière quando a enfermeira Marisa se apresenta de jaleco branco, touca na cabeça e estetoscópio no pescoço cantando os versos "O batuque é uma dança / De cultura popular / Eu convido a Mariinha / Pra nois batuca" em um ambiente que, pela imagem, nos parece hospitalar. Nela, reconhecemos a poética do conhecimento operando o dissenso em prol da memória dessa comunidade de mulheres que se vinculam no afeto contra silenciamentos culturais ainda que façam parte de uma região imersa em desigualdades socioeconômicas agravadas pela pandemia de Covid-19. Desse modo, a partilha dos jogos de versos também é uma partilha estética e afetiva.

\footnotetext{
23 Idem

24 Ibidem

${ }^{25}$ Roda de versos [Post do Instagram]. Disponível em: <https://www.instagram.com/p/CBKz9sSAssz/.> Acesso em: 18 jun. 2020.
} 


\section{Considerações Finais}

Neste artigo, a roda de versos começou com a Dona Nilza e terminou com Marisa. Porém, percebemos que há muitas partilhas na prática do jogo de versos. Uma delas são as narrativas que transmitem as vozes e saberes das bordadeiras e tecelãs do Vale do Jequitinhonha. Por outro lado, durante a pandemia de Covid-19, essas mulheres transformam suas narrativas também em partilha estética, poética e política numa comunidade solidária no afeto.

Aprende-se o jogo de verso com mães, tias, avós, irmãs e amigas, consolidando a coesão do grupo na voz de um mestre que inicia a memória oral. Nesse processo, o corpo se torna mídia e fortalece a teia dos vínculos. Graças às fronteiras semióticas e às trocas culturais das semiosferas midiática, da cultura e do consumo, os jogos de versos, na condição de textos culturais, se atualizam e sedimentam a memória deste grupo social, evitando o seu apagamento no Vale do Jequitinhonha. As narrativas de Dona Nilza, Dona Ana, Dona Mila, Nêga, Marli, Karen, Luciana, Dona Niva, Dona Oraci, Nalva, Jac, Leila, Elaine e Marisa compreendidas nos jogos de versos também operam a partilha política da memória.

\section{Referências}

BAITELLO, N. A serpente, a maçã e o holograma: esboços para uma teoria da mídia. São Paulo: Paulus, 2010.

DOUGLAS, M.; ISHERWOOD, B. O mundo dos bens: para uma antropologia do consumo. Rio de Janeiro: UFRJ, 2006.

FERREIRA, J. P. Cultura é memória. Revista USP, Brasil, n. 24, p. 114-120, fev. 1995. Disponível em: <http://www.revistas.usp.br/revusp/article/view/27032/28806>. Acesso em: junho 2020.

FERREIRA, J. P. Os ofícios tradicionais - Cultura é memória. Revista USP, n. 29, p. 102106, mai. 1996. Disponível em: <http://www.revistas.usp.br/revusp/article/view/25645/27383 > Acesso em: junho 2020

LOTMAN, I. La semiosfera. vol.1. Madrid: Cátedra, 1996. 
MARQUES, Â. C. S.; PRADO, M. A. M. Diálogos e dissidências: Michel Foucault e Jacques Rancière. Curitiba: Appris Editora, 2018.

MENEZES, J. E. O. Processos de mediação: da mídia primária à mídia terciária. Revista Communicare - Volume 4, Edição 1, p. 27-40, $1^{\circ}$ semestre de 2004.

MORIN, E. Sapiens-demens. In.: 0 paradigma perdido: a natureza humana. Lisboa: Publicações Europa América,1973.

PARRET, H. A estética da comunicação: além da pragmática. Campinas, São Paulo: Editora da UNICAMP, 1997.

RANCIÈRE, J. A partilha do sensível: estética e política. São Paulo: Editora 34, 2009.

RANCIÈRE, J. A noite dos proletários. Arquivos do sonho operário. Trad. Marilda Pedreira. São Paulo: Companhia das Letras, 1988.

RICOEUR, P. A memória, a história, o esquecimento. Campinas: Editora Unicamp, 2007.

THOMPSON, P. A voz do passado: história oral. São Paulo: Paz e Terras, 1998.

THOMPSON, P. Histórias de vida como patrimônio da Humanidade In.: História falada: memória, rede e mudança social. (Orgs) WORCMAN, Karen; PEREIRA, Jesus V. São Paulo: SESC SP: Museu da Pessoa: Imprensa Oficial do Estado de São Paulo, 2006. 


\section{Como citar este artigo}

BACEGA, Débora Regina. Jogar verso, bordar memória, cantar poética: a pandemia de Covid-19 e as mulheres do Vale do Jequitinhonha. Revista Dispositiva. [on-line] Disponível em: <http://periodicos.pucminas.br/index.php /dispositiva> Dossiê: Comunicação, política e saúde. Editoras Responsáveis: Fernanda Sanglard e Vanessa Veiga de Oliveira. Volume 9, Número 16, Belo Horizonte, dezembro de 2020, p. 107-123. Acesso em "dia/mês/ano".

Texto recebido em: 24/08/2020

Texto aprovado em: $16 / 11 / 2020$ 